\title{
TITLE:
}

\section{Analytical model for reduction of deep levels in SiC by thermal oxidation}

$\operatorname{AUTHOR}(\mathrm{S})$ :

Kawahara, Koutarou; Suda, Jun; Kimoto, Tsunenobu

\section{CITATION:}

Kawahara, Koutarou ... [et al]. Analytical model for reduction of deep levels in SiC by thermal oxidation. Journal of Applied Physics 2012, 111(5): 053710.

ISSUE DATE:

2012-03

URL:

http://hdl.handle.net/2433/155410

RIGHT:

(C) 2012 American Institute of Physics 


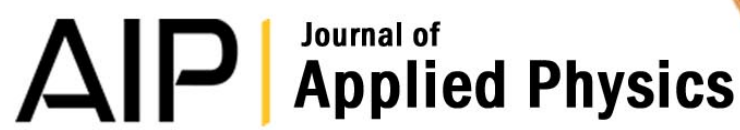

Analytical model for reduction of deep levels in SiC by thermal oxidation

Koutarou Kawahara, Jun Suda, and Tsunenobu Kimoto

Citation: J. Appl. Phys. 111, 053710 (2012); doi: 10.1063/1.3692766

View online: http://dx.doi.org/10.1063/1.3692766

View Table of Contents: http://jap.aip.org/resource/1/JAPIAU/v111/i5

Published by the American Institute of Physics.

\section{Related Articles}

Effect of defect bands in $\beta$-In2S3 thin films

J. Appl. Phys. 111, 093714 (2012)

Defect energy levels and electronic behavior of $\mathrm{Ni}$-, Co-, and As-doped synthetic pyrite (FeS2)

J. Appl. Phys. 111, 083717 (2012)

Defect level distributions and atomic relaxations induced by charge trapping in amorphous silica Appl. Phys. Lett. 100, 172908 (2012)

First principles study of the oxygen vacancy formation and the induced defect states in hafnium silicates J. Appl. Phys. 111, 074106 (2012)

First-principles study of impurities in $\mathrm{TIBr}$

J. Appl. Phys. 111, 073519 (2012)

\section{Additional information on J. Appl. Phys.}

Journal Homepage: http://jap.aip.org/

Journal Information: http://jap.aip.org/about/about_the_journal

Top downloads: http://jap.aip.org/features/most_downloaded

Information for Authors: http://jap.aip.org/authors

\section{ADVERTISEMENT}

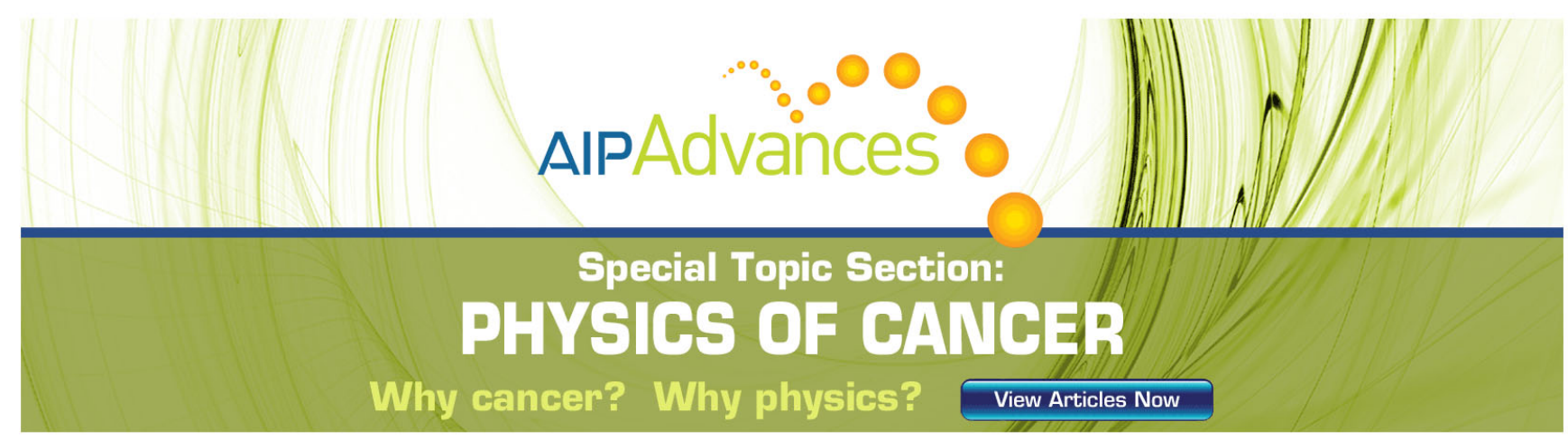




\title{
Analytical model for reduction of deep levels in SiC by thermal oxidation
}

\author{
Koutarou Kawahara, ${ }^{\text {a) }}$ Jun Suda, and Tsunenobu Kimoto ${ }^{\text {b) }}$ \\ Department of Electronic Science and Engineering, Kyoto University, Katsura, Nishikyo, Kyoto, 615-8510, \\ Japan
}

(Received 12 January 2012; accepted 6 February 2012; published online 14 March 2012)

\begin{abstract}
Two trap-reduction processes, thermal oxidation and $\mathrm{C}^{+}$implantation followed by $\mathrm{Ar}$ annealing, have been discovered, being effective ways for reducing the $Z_{1 / 2}$ center $\left(E_{C}-0.67 \mathrm{eV}\right)$, which is a lifetime killer in n-type $4 \mathrm{H}-\mathrm{SiC}$. In this study, it is shown that new deep levels are generated by the trap-reduction processes in parallel with the reduction of the $\mathrm{Z}_{1 / 2}$ center. A comparison of defect behaviors (reduction, generation, and change of the depth profile) for the two trap-reduction processes shows that the reduction of deep levels by thermal oxidation can be explained by an interstitial diffusion model. Prediction of the defect distributions after oxidation was achieved by a numerical calculation based on a diffusion equation, in which interstitials generated at the $\mathrm{SiO}_{2} / \mathrm{SiC}$ interface diffuse to the $\mathrm{SiC}$ bulk and occupy vacancies related to the origin of the $\mathrm{Z}_{1 / 2}$ center. The prediction based on the proposed analytical model is mostly valid for SiC after oxidation at any temperature, for any oxidation time, and any initial $\mathrm{Z}_{1 / 2}$-concentration. Based on the results, the authors experimentally achieved the elimination of the $Z_{1 / 2}$ center to a depth of about $90 \mu \mathrm{m}$ in the sample with a relatively high initial- $Z_{1 / 2}$-concentration of $10^{13} \mathrm{~cm}^{-3}$ by thermal oxidation at $1400{ }^{\circ} \mathrm{C}$ for $16.5 \mathrm{~h}$. Furthermore, prediction of carrier lifetimes in $\mathrm{SiC}$ from the $\mathrm{Z}_{1 / 2}$ profiles was realized through calculation based on a diffusion equation, which considers excited-carrier diffusion and recombination in the epilayer, in the substrate, and at the surface. (C) 2012 American Institute of Physics. [http://dx.doi.org/10.1063/1.3692766]
\end{abstract}

\section{INTRODUCTION}

$\mathrm{SiC}$ has attracted increasing attention as a promising wide-bandgap semiconductor for realizing high-power, hightemperature, and high-frequency devices. One of the dominant obstacles to realizing high-performance $\mathrm{SiC}$ devices is existence of deep levels in $\mathrm{SiC}$ epilayers. Deep levels are generated during epitaxial growth ${ }^{1-4}$ and device fabrication steps such as ion implantation ${ }^{5-10}$ and reactive ion etching. ${ }^{11}$ The deep levels work as recombination centers resulting in reduction of the carrier lifetime ${ }^{12}$ and also work as carrier traps, leading to reduction of the conductivity. Therefore, deep levels, especially the $Z_{1 / 2}$ center, a well known deep level that is a lifetime killer in n-type $4 \mathrm{H}-\mathrm{SiC},{ }^{13,14}$ must be controlled. The typical carrier lifetime for commercially available SiC epilayers is only $0.6-1 \mu$ s due to the high $\mathrm{Z}_{1 / 2}$ concentration of about $10^{13} \mathrm{~cm}^{-3}$, while over $5 \mu$ s lifetime is required for $10 \mathrm{kV} \mathrm{PiN}$-diodes.

The origin of $Z_{1 / 2}$ center has been extensively investigated. ${ }^{1,3,15,16}$ The authors speculate that $Z_{1 / 2}$ center is a carbon-vacancy $\left(\mathrm{V}_{\mathrm{C}}\right)$-related defect because of the following three experimental results. First, the $\mathrm{Z}_{1 / 2}$ center is generated by low-energy (100-200 keV) electron irradiation, which displaces only $\mathrm{C}$ atoms, without subsequent annealing. ${ }^{3,15}$ Second, the $\mathrm{Z}_{1 / 2}$ concentration is lower in the samples grown under $\mathrm{C}$-rich condition (higher $\mathrm{C} / \mathrm{Si}$ ratio). ${ }^{17}$ Third, the $\mathrm{Z}_{1 / 2}$ is a thermally stable defect, ${ }^{1}$ showing no change of concentration up to $1600{ }^{\circ} \mathrm{C},{ }^{3}$ at which temperature interstitials can

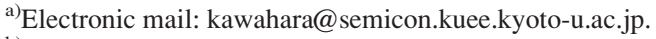

${ }^{b}$ Also at Photonics and Electronics Science and Engineering Center (PESEC), Kyoto University.
}

easily diffuse. Additionally, it has been reported that the energy levels and the negative $U$ nature originating from $V_{C}$ obtained by ab initio calculation (density functional theory) are in agreement with the properties of the $\mathrm{Z}_{1 / 2}$ center detected by deep level transient spectroscopy (DLTS). ${ }^{18}$

There are two effective methods to reduce the $Z_{1 / 2}$ center: (i) $\mathrm{C}^{+}$implantation followed by Ar annealing ${ }^{19,20}$ and (ii) thermal oxidation. ${ }^{21}$ In the case of the $\mathrm{C}^{+}$-implantation process, implanted excess carbon atoms should diffuse to the deeper region of an $\mathrm{SiC}$ epilayer during post-implantation annealing and fill $\mathrm{V}_{\mathrm{C}}$, resulting in reduction of the $\mathrm{Z}_{1 / 2}$ concentration. ${ }^{20}$ In the case of thermal oxidation, the $Z_{1 / 2}$ reduction may be ascribed to diffusion of interstitials generated at the $\mathrm{SiO}_{2} / \mathrm{SiC}$ interface during oxidation ${ }^{21}$ as shown in Fig. 1. There are several reports indicating the generation of interstitials at the $\mathrm{SiO}_{2} / \mathrm{SiC}$ interface, ${ }^{22-24}$ which support this trap reduction model. (i) Experimental oxidation rate of $\mathrm{SiC}$ can be well simulated by considering silicon and carbon emission from the oxidation interface. ${ }^{22}$ (ii) An increase of carbon atom concentration at the $\mathrm{SiO}_{2} / \mathrm{SiC}$ interface was observed by electron energy loss spectroscopy. ${ }^{23}$ (iii) It has been predicted from $a b$ initio calculation that carbon clusters are formed at the $\mathrm{SiO}_{2} / \mathrm{SiC}$ interface during oxidation. ${ }^{24}$ The trap reduction mechanism by thermal oxidation, however, has not been fully understood.

The purposes of this study are to ascertain the trapreduction model shown in Fig. 1 and to enable prediction of the depth profiles of deep levels after oxidation in order to control deep levels by thermal oxidation. For these purposes, the authors compare deep levels in the SiC epilayers after the $\mathrm{C}^{+}$-implantation process and those after thermal oxidation, and investigate the oxidation-temperature dependence, 


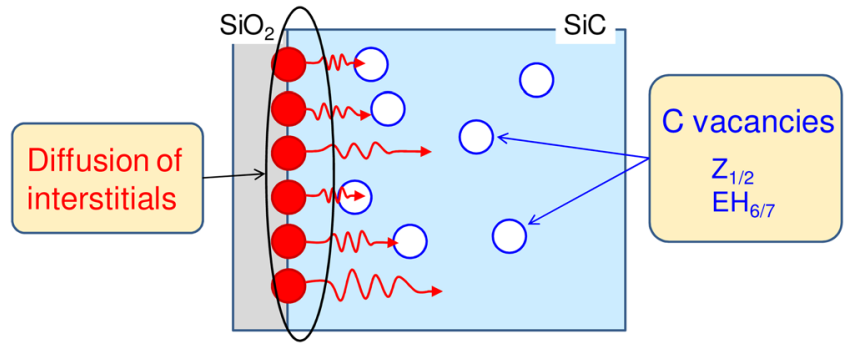

FIG. 1. (Color online) Schematic model for reduction of the $\mathrm{Z}_{1 / 2}$ and $\mathrm{EH}_{6 / 7}$ centers during oxidation. Interstitials generated at the $\mathrm{SiO}_{2} / \mathrm{SiC}$ interface diffuse into $\mathrm{SiC}$ bulk, and occupy carbon vacancies related to the $\mathrm{Z}_{1 / 2}$ and $\mathrm{EH}_{6 / 7}$ centers.

oxidation-time dependence, and initial- $Z_{1 / 2}$-concentration dependence of the defect reduction in both n-type and p-type 4H-SiC epilayers. Based on these data, an analytical model of defect reduction as well as the most effective way to reduce the $Z_{1 / 2}$ center are proposed. In addition, the effect of the $Z_{1 / 2}$ reduction on the carrier lifetime is investigated through the relation between the carrier lifetime and the $Z_{1 / 2}$ depth-profile after the oxidation process under various conditions.

\section{EXPERIMENTS}

The starting materials were n-type $\left(N_{\mathrm{d}}: 10^{14}-10^{15}\right.$ $\left.\mathrm{cm}^{-3}\right)$ and p-type $\left(N_{\mathrm{a}}: 10^{15}-10^{16} \mathrm{~cm}^{-3}\right) 4 \mathrm{H}-\mathrm{SiC}(0001)$ epilayers. A series of samples was oxidized at different temperatures $\left(1150-1400{ }^{\circ} \mathrm{C}\right)$ for various times $(1.3-16.5 \mathrm{~h})$ in $100 \%$ oxygen ambient, while the other set of samples was implanted with $10-50 \mathrm{keV}$ carbon ions with a total dose of $1 \times 10^{13} \mathrm{~cm}^{-2}$ or $1 \times 10^{14} \mathrm{~cm}^{-2}$ (implanted atom concentration: $1 \times 10^{18} \mathrm{~cm}^{-3}$ or $1 \times 10^{19} \mathrm{~cm}^{-3}$ ), forming a $140-\mathrm{nm}$ box-profile. The $\mathrm{C}^{+}$-implanted samples were annealed in $\mathrm{Ar}$ ambient at various temperatures $\left(1000-1800^{\circ} \mathrm{C}\right)$ for $20 \mathrm{~min}$. For DLTS measurements, $\mathrm{Ni}$ and $\mathrm{Ti}$ were employed as Schottky contacts on n-type and p-type samples, respectively. The typical diameter of Schottky contacts was $1 \mathrm{~mm}$. A Ti/Al/Ni $(20 \mathrm{~nm} / 100 \mathrm{~nm} / 80 \mathrm{~nm})$ layer annealed at $1000{ }^{\circ} \mathrm{C}$ for $2 \mathrm{~min}$ was employed as backside ohmic contacts for p-type materials. A period width of $0.205 \mathrm{~s}$ was employed for all DLTS measurements performed in this study. The depth profiles of deep-level concentrations until $10-\mu \mathrm{m}$ depth were measured by changing the reverse bias voltage up to $100 \mathrm{~V}$ in DLTS measurements. To monitor deeper regions (over $10 \mu \mathrm{m}$ ), the samples were mechanically polished from the surfaces, and DLTS measurements were repeated. It was confirmed that additional deep levels did not appear after the polishing. The carrier lifetime was measured at room temperature by microwave photoconductance decay ( $\mu$-PCD) equipped with an yttrium lithium fluoride-third harmonic generation laser $(\lambda=349 \mathrm{~nm})$ as an excitation source.

\section{RESULTS AND DISCUSSION}

\section{A. Defect distributions after trap reduction processes}

At first, deep levels after the two trap-reduction processes are compared. Figure 2 and 3 shows the DLTS spectra of the n-type/p-type samples after dry oxidation at $1300{ }^{\circ} \mathrm{C}$

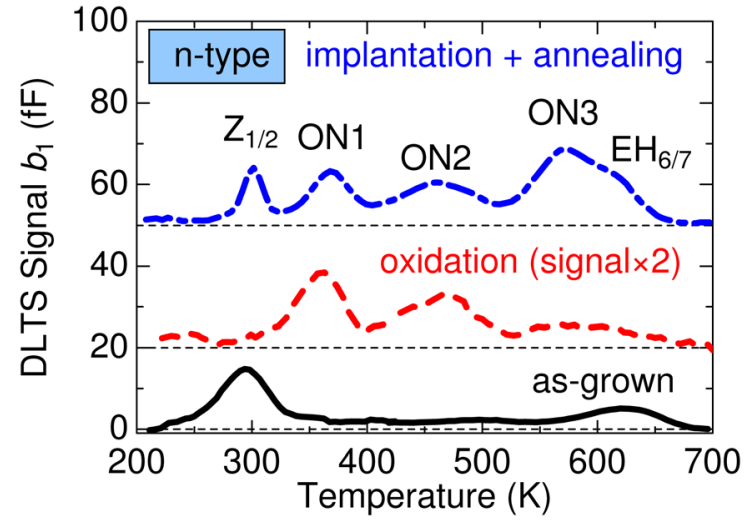

FIG. 2. (Color online) DLTS spectra of the n-type 4H-SiC after thermal oxidation at $1300{ }^{\circ} \mathrm{C}$ for $1.3 \mathrm{~h}$ (dashed line) and $\mathrm{C}^{+}$implantation followed by Ar annealing at $1800^{\circ} \mathrm{C}$ for $20 \mathrm{~min}$ (dashed-dotted line).

for $1.3 \mathrm{~h}$, as well as the samples after $\mathrm{C}^{+}$implantation (dose: $1 \times 10^{14} \mathrm{~cm}^{-2}$ ) and subsequent Ar-annealing at $1800^{\circ} \mathrm{C} /$ $1300{ }^{\circ} \mathrm{C}$ for $20 \mathrm{~min}$. Here, the signal $b_{1}$ is the coefficient of the first sine term in the Fourier series of deep level transient Fourier spectroscopy. ${ }^{25}$ After the $\mathrm{C}^{+}$-implantation process (dashed-dotted lines), the new peaks, ON1 $\left(E_{\mathrm{C}}-0.84 \mathrm{eV}\right)$, ON2 $\left(E_{\mathrm{C}}-1.1 \mathrm{eV}\right)$, and ON3 $\left(E_{\mathrm{C}}-1.6 \mathrm{eV}\right)$ in n-type $\mathrm{SiC}$ (Fig. 2), and HK0 (Refs. 4 and 26) $\left(E_{\mathrm{V}}+0.79 \mathrm{eV}\right)$ in p-type $\mathrm{SiC}$ (Fig. 3), appeared, while the same four peaks are also observed after thermal oxidation (dashed lines). The ON1 and ON2 centers should correspond to the deep levels reported as "new traps" in $\mathrm{SiC}$ after $\mathrm{C}^{+}$-implantation process. ${ }^{20}$ On the other hand, two major deep levels, $\mathrm{Z}_{1 / 2}\left(E_{\mathrm{C}}-0.67 \mathrm{eV}\right)$ and $\mathrm{EH}_{6 / 7}\left(E_{\mathrm{C}}-1.6 \mathrm{eV}\right)$, are reduced in n-type $\mathrm{SiC}$ after thermal oxidation as shown by the dashed line in Fig. 2 . The $Z_{1 / 2}$ and $\mathrm{EH}_{6 / 7}$ centers are also reduced to below the detection limit by $\mathrm{C}^{+}$implantation followed by $\mathrm{Ar}$ annealing at $1500^{\circ} \mathrm{C}$ (not shown), while they are regenerated by high-temperature (over $1700^{\circ} \mathrm{C}$ ) annealing as shown by the dashed-dotted line in Fig. 2. The reduced deep levels as well as generated levels by the trap-reduction processes are summarized in Table I. The defect behaviors (generation and reduction) for thermal oxidation clearly agree with those for the $\mathrm{C}^{+}$-implantation process, which indicates that similar phenomena (such as interstitial diffusion) may occur in the two processes.

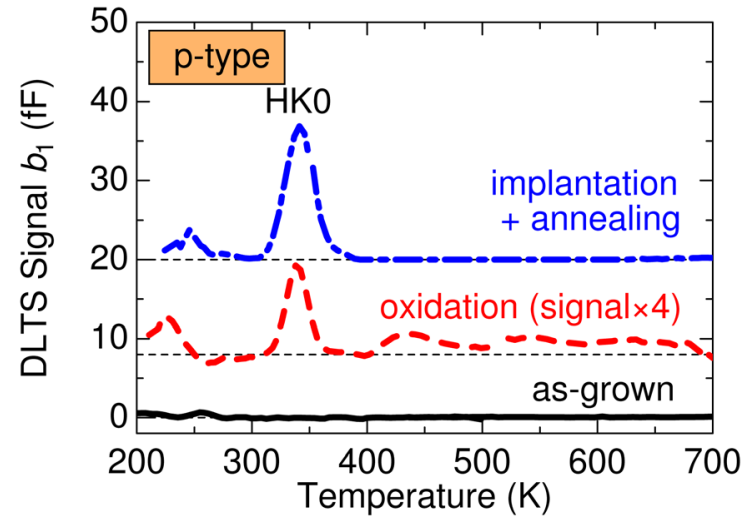

FIG. 3. (Color online) DLTS spectra of the p-type 4H-SiC after thermal oxidation at $1300^{\circ} \mathrm{C}$ for $1.3 \mathrm{~h}$ (dashed line) and $\mathrm{C}^{+}$implantation followed by Ar annealing at $1300^{\circ} \mathrm{C}$ for $20 \mathrm{~min}$ (dashed-dotted line). 
TABLE I. Reduced and generated defects in $\mathrm{SiC}$ by $\mathrm{C}^{+}$-implantation process and by thermal oxidation. The conduction types of the samples where each defect is observed are shown in parentheses.

\begin{tabular}{lccc}
\hline \hline \multicolumn{2}{c}{$\mathrm{C}^{+}$implantation + Ar annealing } & \multicolumn{2}{c}{ Thermal oxidation } \\
\hline Reduced defects & Generated defects & Reduced defects & Generated defects \\
\hline $\mathrm{Z}_{1 / 2}$ (n-type) & ON1 (n-type) & $\mathrm{Z}_{1 / 2}$ (n-type) & ON1 (n-type) \\
$\mathrm{EH}_{6 / 7}$ (n-type) & ON2 (n-type) & $\mathrm{EH}_{6 / 7}$ (n-type) & ON2 (n-type) \\
& ON3 (n-type) & & ON3 (n-type) \\
& HK0 (p-type) & & HK0 (p-type) \\
\hline \hline
\end{tabular}

It is important to investigate the depth profiles of generated and reduced defects in order to understand what phenomena occur during the trap-reduction processes. Figure 4 shows the depth profiles of ON1 center (generated defect) after oxidation at various temperatures for $1.3 \mathrm{~h}$. With increasing oxidation temperature, the ON1 concentration increases and is distributed to a deeper region, suggesting that the ON1 center is related to the atoms, most likely interstitials, diffused from the $\mathrm{SiO}_{2} / \mathrm{SiC}$ interface. The ON2 and $\mathrm{HK} 0$ centers (generated defects) showed similar behavior (not shown). Figure 5 shows the depth profiles of $Z_{1 / 2}$ center (reduced defect) after oxidation at various temperatures for $1.3 \mathrm{~h}$. In this particular case, the initial $\mathrm{Z}_{1 / 2}$ concentration was increased to $1.7 \times 10^{14} \mathrm{~cm}^{-3}$ by electron irradiation (energy: $150 \mathrm{keV}$, fluence: $1 \times 10^{17} \mathrm{~cm}^{-2}$ ) in order to investigate trap reduction in the sample with high initial- $\mathrm{Z}_{1 / 2^{-} \text {-con- }}$ centration. With increasing oxidation temperature, the $Z_{1 / 2}$ concentration decreases and is eliminated to a deeper region, suggesting that the $Z_{1 / 2}$ center is related to the (carbon) vacancies, which are occupied by diffused interstitials during oxidation. In addition, the depth of the $\mathrm{Z}_{1 / 2}$-elimination region is proportional to the square root of the oxidation time $\left(t_{\mathrm{ox}}^{1 / 2}\right) .{ }^{21}$ These results clearly suggest that the diffusion phenomena is taking place in the $\mathrm{SiC}$ bulk region during thermal oxidation.

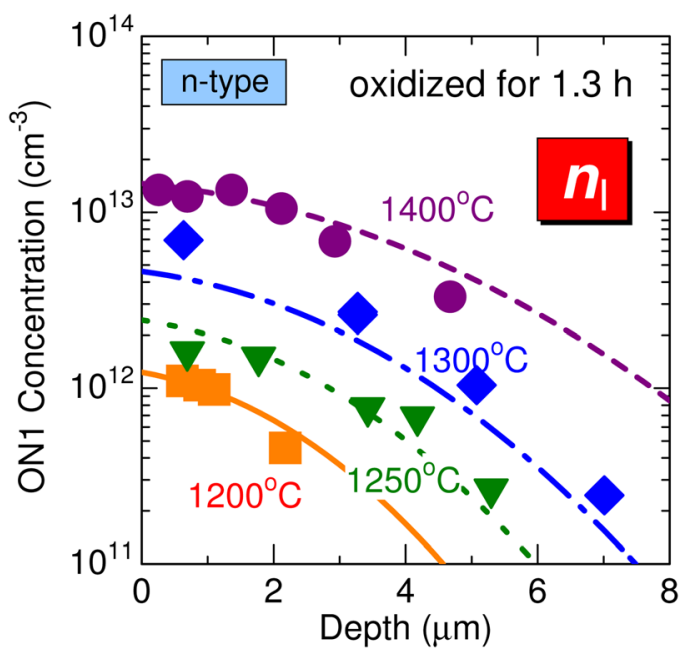

FIG. 4. (Color online) Depth profiles of ON1 center after oxidation at various temperatures for $1.3 \mathrm{~h}$. Each symbol indicates the experimental data and each line indicates the calculated $n_{\mathrm{I}}$ distribution obtained from Eqs. (1)-(8).

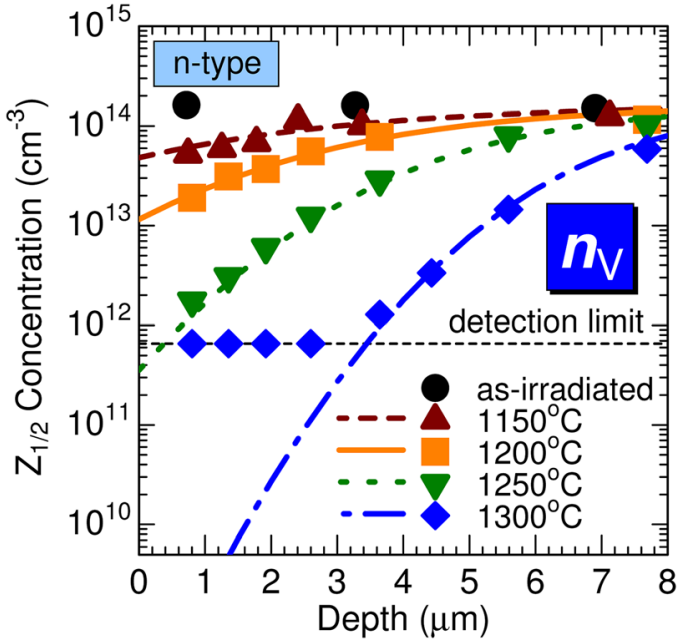

FIG. 5. (Color online) Depth profiles of $Z_{1 / 2}$ center after oxidation at various temperatures for $1.3 \mathrm{~h}$. The initial $\mathrm{Z}_{1 / 2}$-concentration is $1.7 \times 10^{14}$ $\mathrm{cm}^{-3}$. Each symbol indicates the experimental data and each line indicates the calculated $n_{\mathrm{V}}$ distribution obtained from Eqs. (1)-(8).

\section{B. Analytical model for defect distributions after thermal oxidation}

As discussed above, the reduction of the $\mathrm{Z}_{1 / 2}$ center by oxidation can be explained by diffusion of interstitials and recombination with vacancies as shown in Fig. 1. Therefore, to predict defect distributions after thermal oxidation, the following diffusion equations are solved.

Evolution equations

$$
\begin{gathered}
\frac{\partial n_{\mathrm{I}}}{\partial t}=D \cdot \frac{\partial^{2} n_{\mathrm{I}}}{\partial x^{2}}-\gamma \cdot n_{\mathrm{I}} \cdot n_{\mathrm{V}}, \\
\frac{\partial n_{\mathrm{V}}}{\partial t}=-\gamma \cdot n_{\mathrm{I}} \cdot n_{\mathrm{V}} .
\end{gathered}
$$

Boundary and initial conditions

$$
\begin{gathered}
-\left.D \cdot \frac{\partial n_{\mathrm{I}}}{\partial x}\right|_{x=0}=F_{0} \cdot t^{-\alpha}(t \neq 0), \\
\left.n_{\mathrm{I}}\right|_{t=0}=0, \\
\left.n_{\mathrm{V}}\right|_{t=0}=n_{\mathrm{V} 0} .
\end{gathered}
$$

Fitting parameters

$$
\begin{gathered}
D=D_{\infty} \cdot \exp \left(-\frac{E_{\mathrm{aD}}}{k T}\right), \\
F_{0}=F_{0 \infty} \cdot \exp \left(-\frac{E_{\mathrm{aF}}}{k T}\right), \\
\gamma=\gamma_{\infty} \cdot \exp \left(-\frac{E_{\mathrm{a} \gamma}}{k T}\right),
\end{gathered}
$$

where $n_{\mathrm{I}}$ and $n_{\mathrm{V}}$ are the concentrations of interstitials and vacancies, latter of which is related to the origin of $\mathrm{Z}_{1 / 2}$ center. $D$ denotes the diffusion coefficient of the interstitials, and $\gamma$ is the recombination coefficient between an interstitial and a vacancy. In this model, vacancies are assumed to be 
immobile and decrease through the recombination with diffused interstitials as described in Eq. (2). Equation (3) indicates the boundary condition of interstitial emission at the oxidation interface, which is described with $F_{0}$ : flux of interstitials emitted from the $\mathrm{SiO}_{2} / \mathrm{SiC}$ interface when $t_{\text {ox }}=1 \mathrm{~s}$ $\left(t_{\mathrm{ox}}\right.$ : oxidation time). Since the oxidation rate becomes slow with the time, the gradual decrease in flux of emitted interstitials as the oxidation (time) proceeds is considered by introducing a slowdown coefficient $\alpha$. The flux of interstitials should be in proportion to the oxidation rate. The slowdown of the oxidation reaction at the interface can be estimated from Fig. 6, which shows the dependence of the oxide growth rate on oxidation time at different oxidation temperatures. A result on oxidation at $1100{ }^{\circ} \mathrm{C}$ reported by Hijikata et al. (Ref. 22) is also plotted in the same figure. When the slope of the plot is described as $-\alpha$, the oxidation rate is proportional to $t_{\mathrm{ox}}^{-\alpha}$. Therefore, interstitial emission can be assumed to decrease in proportion to $t_{\mathrm{ox}}^{-\alpha}$ as shown in Eq. (3). For simplicity, the time-dependent oxidation-rate is expressed in two stages; high-oxidation-rate stage $\left(t_{\mathrm{ox}}<0.8\right.$ h), where $\alpha$ is unity for $1150-1300{ }^{\circ} \mathrm{C}$ oxidation and 0.48 for $1400^{\circ} \mathrm{C}$ oxidation; and low-oxidation-rate stage $\left(0.8 \mathrm{~h}<t_{\text {ox }}\right)$, where $\alpha$ is 0.23 for $1150-1300^{\circ} \mathrm{C}$ oxidation and 0.48 for $1400^{\circ} \mathrm{C}$ oxidation. It is assumed that $n_{\mathrm{I}}$ before oxidation is negligible compared with that after oxidation as described in Eq. (4). A parameter $n_{\mathrm{V} 0}$ in Eq. (5) denotes the initial vacancy distribution before oxidation. As shown in Eqs. (6)-(8), each parameter is described as a function of temperature. The parameters, $E_{\mathrm{aD}}, E_{\mathrm{aF}}$, and $E_{\mathrm{a} \gamma}$, indicate the activation energy corresponding to the energy barrier for migration of interstitials, that for generation of interstitials, and that for recombination of interstitials with vacancies, respectively.

\section{Comparison between experimental $Z_{1 / 2}$ profile and calculated vacancy profile after thermal oxidation}

Based on Eqs. (1)-(8), the depth profiles of $n_{\mathrm{I}}$ and $n_{\mathrm{V}}$ can be calculated, which are dependent on six fitting parameters: $E_{\mathrm{aD}}, D_{\infty}, E_{\mathrm{aF}}, F_{0 \infty}, E_{\mathrm{a} \gamma}$, and $\gamma_{\infty}$. As mentioned, the

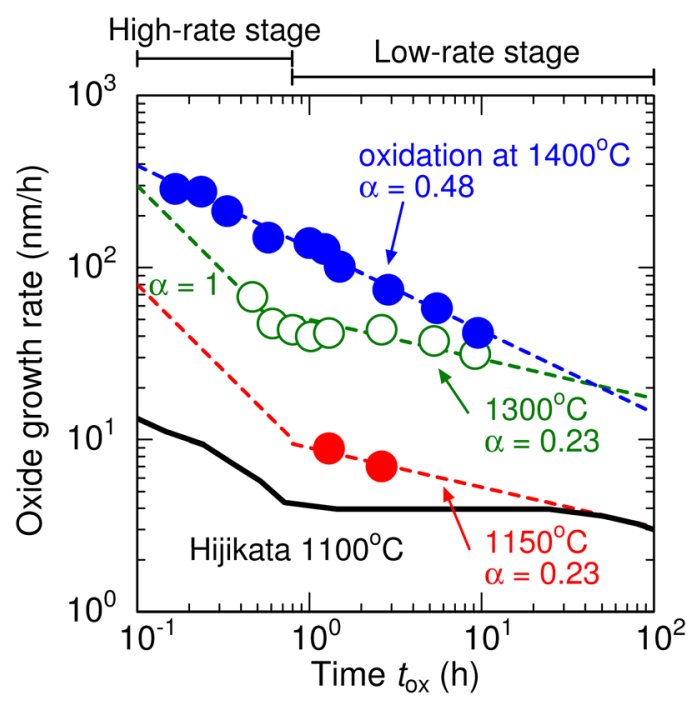

FIG. 6. (Color online) Dependence of the oxide growth rate on oxidation time at different oxidation temperatures. A result $\left(1100^{\circ} \mathrm{C}\right)$ reported by Hijikata $e a^{22}$ is also shown as a solid line.

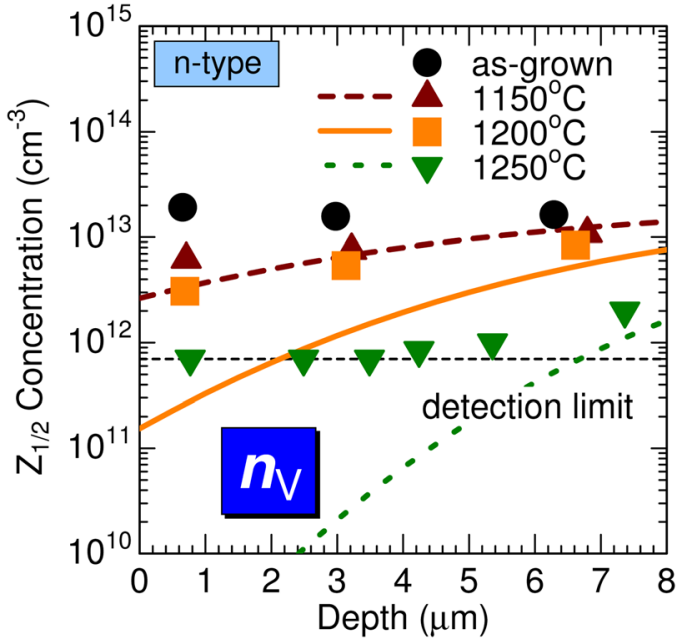

FIG. 7. (Color online) Depth profiles of $Z_{1 / 2}$ center after oxidation at various temperatures for $1.3 \mathrm{~h}$. The initial $\mathrm{Z}_{1 / 2}$-concentration is $2 \times 10^{13} \mathrm{~cm}^{-3}$. Each symbol indicates the experimental data and each line indicates the calculated $n_{\mathrm{V}}$ distribution obtained from Eqs. (1)-(8).

authors experimentally obtained the depth profiles of $\mathrm{Z}_{1 / 2}$ concentration after oxidation at different temperatures for several samples with different initial $\mathrm{Z}_{1 / 2}$ concentrations. Symbols in Figs. 5 and 7 show the experimental results for the samples with an initial $Z_{1 / 2}$ concentration of $1.7 \times 10^{14}$ $\mathrm{cm}^{-3}$ and $2.0 \times 10^{13} \mathrm{~cm}^{-3}$. These experimental depth profiles of $\mathrm{Z}_{1 / 2}$ concentration were fitted with the $n_{\mathrm{V}}$ profiles calculated from Eqs. (1)-(8). In the calculation, arbitrary $n_{\mathrm{V}}$ profile can be obtained by changing $D, F_{0}$, and $\gamma$. Fig. 8 shows the effects of changing these three parameters, $D, F_{0}$, and $\gamma$, on the calculated $n_{\mathrm{V}}$ profile. When $D$ becomes higher, $n_{\mathrm{V}}$ becomes relatively higher in the shallow region and lower in the deep region as shown by the dashed line, while opposite phenomena occur in the case of higher $\gamma$ as shown by the dashed-dotted line. Higher $F_{0}$ leads lower $n_{\mathrm{V}}$ in the whole depth region as shown by the dotted line. The fitting parameters are uniquely determined through fitting of a series of $\mathrm{Z}_{1 / 2}$ profiles in the samples with different initial- $\mathrm{Z}_{1 / 2^{-}}$

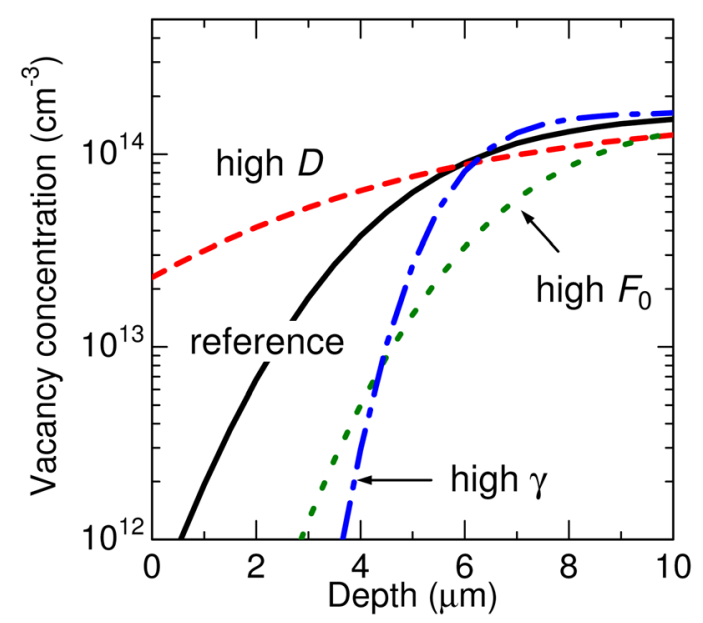

FIG. 8. (Color online) Effects of changing parameters, $D, F_{0}$, and $\gamma$, on calculated $n_{\mathrm{V}}$ profile. Higher $D / F_{0} / \gamma$ is used in the calculation for dashed/dotted/dashed-dotted line compared to the calculation for reference (solid line). 
TABLE II. Parameter values obtained by fitting results of calculated $n_{\mathrm{V}}$ profiles based on Eqs. (1)-(8) and experimental $\mathrm{Z}_{1 / 2}$ profiles shown in Fig. 5. The top row indicates the " $\mathrm{X}$ " in the first column.

\begin{tabular}{lccc}
\hline \hline & $D$ & $F_{0}$ & $\gamma$ \\
\hline Activation energy $E_{\mathrm{ax}}$ & $0.6 \mathrm{eV}$ & $1.4 \mathrm{eV}$ & $2.1 \mathrm{eV}$ \\
Coefficient $X_{\infty}$ & $9.7 \times 10^{-9} \mathrm{~cm}^{2} \mathrm{~s}^{-1}$ & $4.4 \times 10^{14} \mathrm{~cm}^{-2} \mathrm{~s}^{\alpha-1}$ & $1.4 \times 10^{-10} \mathrm{~cm}^{3} \mathrm{~s}^{-1}$ \\
\hline \hline
\end{tabular}

concentration after oxidation at different temperature. The calculated $n_{\mathrm{V}}$ profiles after the fitting are shown as curve lines in Figs. 5 and 7. The obtained values of fitting parameters are summarized in Table II, which are used in all cases in this study. The activation energy for diffusion coefficient $\left(E_{\mathrm{aD}}\right)$ of interstitials reducing the $\mathrm{Z}_{1 / 2}$ center was determined as $0.6 \mathrm{eV}$ in this study. On the other hand, the migration barrier for carbon/silicon interstitials in n-type $\mathrm{SiC}$ has been reported to be $(0.5-0.7) \mathrm{eV} /(1.4-1.5) \mathrm{eV}$ by Bockstedte et al. based on theoretical calculation using density functional theory in the local density approximation, ${ }^{27}$ and by Gao et al. using molecular dynamics simulations. ${ }^{28}$ The activation energy for the diffusion coefficient of interstitials obtained in this study $(0.6 \mathrm{eV})$ agrees with the reported migration energy for carbon interstitials $(0.5-0.7 \mathrm{eV})$, which is consistent with the model that carbon interstitials diffuse from the oxidation interface and fill carbon vacancies.

Using the same parameter values shown in the Table II, the oxidation-time dependence of $Z_{1 / 2}$ profiles was predicted assuming that the $n_{\mathrm{V}}$ profile corresponds to the $\mathrm{Z}_{1 / 2}$ profile. The results are shown as curved lines in Fig. 9 (initial $Z_{1 / 2}$ concentration: $1.3 \times 10^{13} \mathrm{~cm}^{-3}$ ) and Fig. 10 (initial $\mathrm{Z}_{1 / 2}$ concentration: $2 \times 10^{12} \mathrm{~cm}^{-3}$ ) for $1300^{\circ} \mathrm{C}$ oxidation, while corresponding experimental data are shown as symbols in the same figures. The depth profiles of $Z_{1 / 2}$ concentration after various oxidation conditions show very good agreement with the calculated $n_{\mathrm{V}}$ profiles. (Note that these are not fitted results but the $n_{\mathrm{V}}$ profiles were calculated before experiments.) This agreement indicates the potential to enable prediction of the $\mathrm{Z}_{1 / 2}$ distributions after oxidation at any

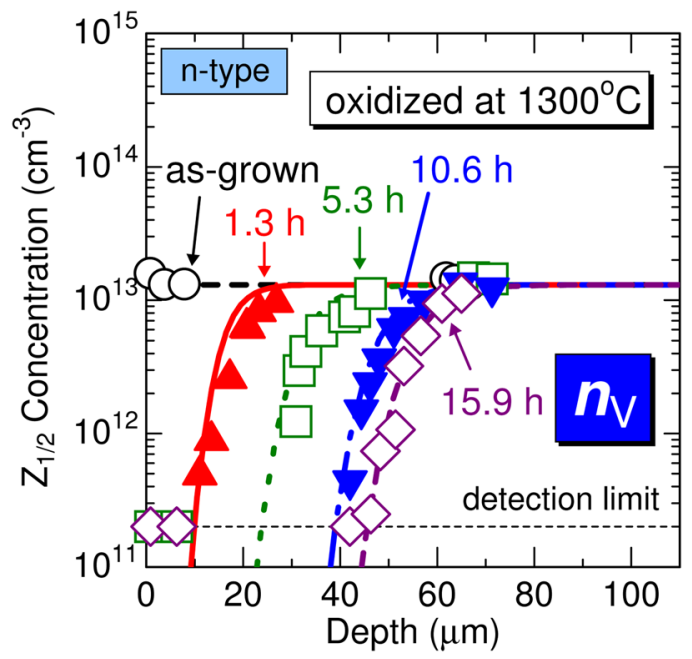

FIG. 9. (Color online) Depth profiles of $\mathrm{Z}_{1 / 2}$ center (initial $\mathrm{Z}_{1 / 2}$-concentration: $1.3 \times 10^{13} \mathrm{~cm}^{-3}$ ) after oxidation at $1300^{\circ} \mathrm{C}$ for $1.3-15.9 \mathrm{~h}$. Each symbol indicates the experimental data and each line indicates the calculated $n_{\mathrm{V}}$ distribution. temperature, for any oxidation time, and any initial $\mathrm{Z}_{1 / 2}$ concentration.

\section{Realization of $100-\mu \mathrm{m} \mathrm{Z} Z_{1 / 2}$-free region}

The authors tried to eliminate the $Z_{1 / 2}$ center to a 100 $\mu \mathrm{m}$ depth, which is required for $10-\mathrm{kV}$-class bipolar devices. Figure 11 shows the calculated results of the $\mathrm{Z}_{1 / 2}\left(n_{\mathrm{V}}\right)$ profiles for various oxidation times and different initial $Z_{1 / 2}$ concentrations $\left(2 \times 10^{12} \mathrm{~cm}^{-3}, 1.3 \times 10^{13} \mathrm{~cm}^{-3}\right)$ using the parameters obtained in this study (Table II). When the initial $\mathrm{Z}_{1 / 2}$ concentration is low, $2 \times 10^{12} \mathrm{~cm}^{-3}$, oxidation at $1300^{\circ} \mathrm{C}$ for $30 \mathrm{~h}$ is enough for $\mathrm{Z}_{1 / 2}$ elimination in the 100 $\mu \mathrm{m}$-thick $\mathrm{SiC}$ epilayer. However, in the case of high initial $\mathrm{Z}_{1 / 2}$ concentration $\left(>10^{13} \mathrm{~cm}^{-3}\right)$, oxidation over $50 \mathrm{~h}$ is required to eliminate the $Z_{1 / 2}$ center. To minimize the oxidation time, the authors propose three approaches: (i) removing the oxide layer during oxidation, (ii) high-temperature annealing after oxidation, and (iii) higher-temperature oxidation.

(i) Removing the oxide layer during oxidation: In the initial oxidation stage, the interstitial emission rate from the $\mathrm{SiO}_{2} / \mathrm{SiC}$ interface is high, as shown in Fig. 6. Therefore, removing the oxide layer during oxidation should promote the interstitial emission and thereby $Z_{1 / 2}$ reduction. Figure 12 shows the depth profiles of $Z_{1 / 2}$ center after oxidation at $1300^{\circ} \mathrm{C}$ for $15.9 \mathrm{~h}$. Each line indicates an $n_{\mathrm{V}}$ profile calculated with the parameters shown in the Table II, and each symbol indicates experimental data. The rhombuses denote the result for continuous 15.9-h oxidation, and reverse

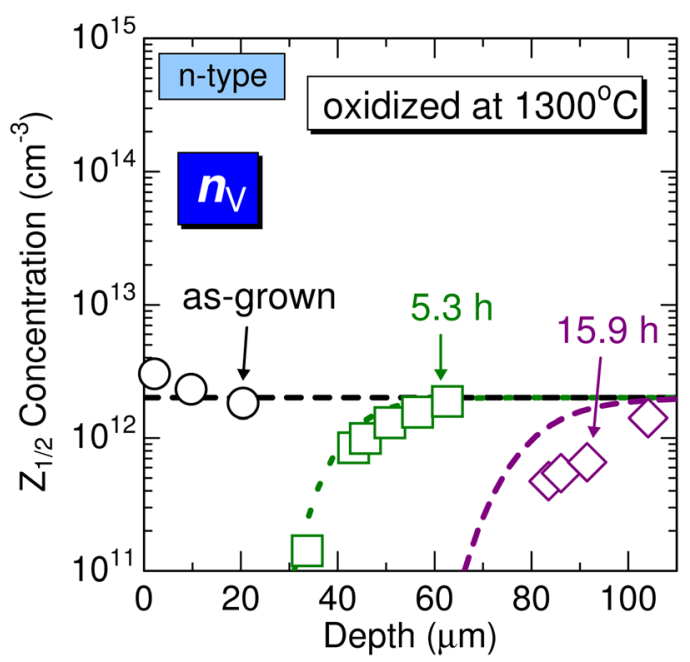

FIG. 10. (Color online) Depth profiles of $\mathrm{Z}_{1 / 2}$ center (initial $\mathrm{Z}_{1 / 2}$-concentration: $2 \times 10^{12} \mathrm{~cm}^{-3}$ ) after oxidation at $1300^{\circ} \mathrm{C}$ for 5.3-15.9 h. Each symbol indicates the experimental data and each line indicates the calculated $n_{\mathrm{V}}$ distribution. 


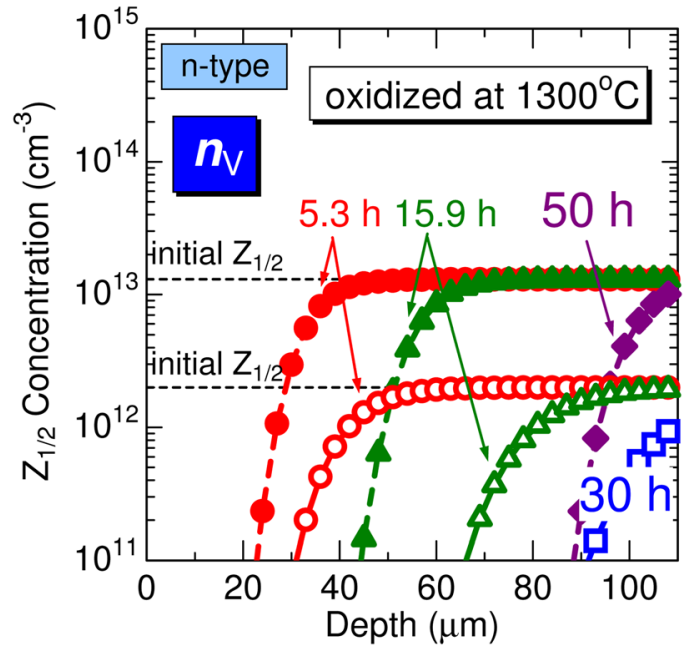

FIG. 11. (Color online) Calculated results of $Z_{1 / 2}$ profiles for various oxidation times and different initial- $Z_{1 / 2}$-concentrations $\left(2 \times 10^{12} \mathrm{~cm}^{-3}\right.$, $1.3 \times 10^{13} \mathrm{~cm}^{-3}$ ) using the parameters obtained in this study. It was assumed that $n_{\mathrm{V}}$ corresponds to the $\mathrm{Z}_{1 / 2}$ concentration.

triangles for 15.9-h oxidation with removing the oxide layer after every 5.3-h oxidation. Removing the oxide layer is clearly effective for enhancing the reduction of the $Z_{1 / 2}$ center. In the calculation, the effect of removing oxide layer is included by resetting the flux of emitted interstitials, which decreases as the oxidation proceeds, to the initial value after every (in this case $5.3 \mathrm{~h}$ ) oxidation. The good agreement between experimental data and calculated results again supports the analytical model for trap reduction proposed in this study.

(ii) High-temperature annealing after oxidation: Diffused interstitials should remain in an epilayer after oxidation. Therefore, subsequent high-temperature annealing should enhance diffusion of the residual interstitials to the deeper region and promote $Z_{1 / 2}$ reduction. Figure 13 shows the $\mathrm{Z}_{1 / 2}$ profiles after oxidation as well as after oxidation

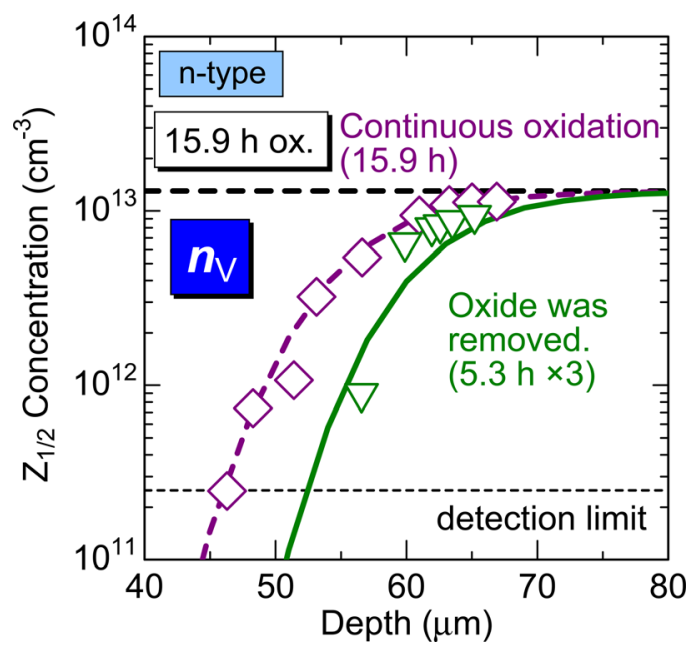

FIG. 12. (Color online) Depth profiles of $\mathrm{Z}_{1 / 2}$ center after oxidation at $1300^{\circ} \mathrm{C}$ for $15.9 \mathrm{~h}$. The rhombuses denote the experimental result for continuous 15.9-h oxidation (dashed line: calculated $n_{\mathrm{V}}$ result with the parameters in Table II), and reverse triangles for 15.9-h oxidation with removing the oxide layer after every 5.3-h oxidation (solid line: calculated $n_{\mathrm{V}}$ result with the parameters in Table II).

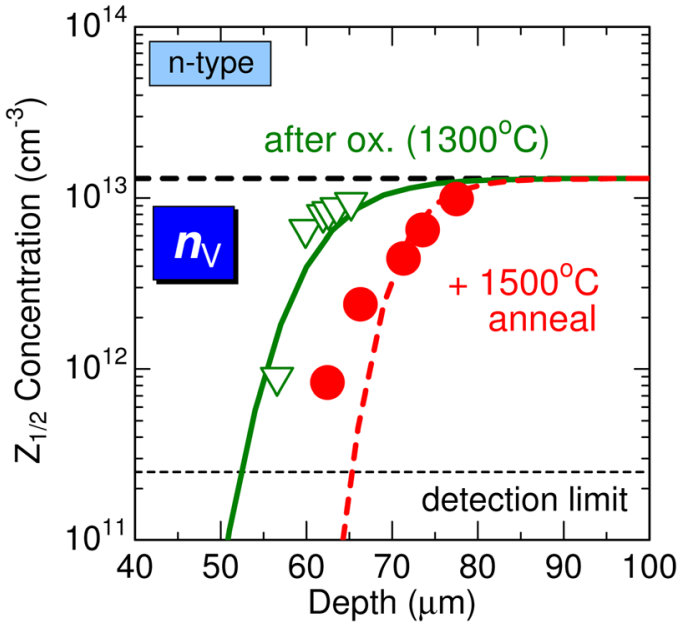

FIG. 13. (Color online) $\mathrm{Z}_{1 / 2}$ profiles after oxidation and after oxidation followed by $1500^{\circ} \mathrm{C}$ annealing. The reverse triangles denote the experimental result for after oxidation at $1300{ }^{\circ} \mathrm{C}$ for $15.9 \mathrm{~h}$ (solid line: calculated $n_{\mathrm{V}}$ result with the parameters in Table II), and the closed circles for the oxidation and subsequent annealing at $1500^{\circ} \mathrm{C}$ for $2 \mathrm{~h}$ in $\mathrm{Ar}$ ambient (dashed line: calculated $n_{\mathrm{V}}$ result with the parameters in Table II).

and subsequent high-temperature $\left(1500^{\circ} \mathrm{C}\right)$ annealing. The solid line indicates the calculated $n_{\mathrm{V}}$ profile just after oxidation at $1300^{\circ} \mathrm{C}$ for $15.9 \mathrm{~h}$, and the dashed line denotes that after oxidation and subsequent annealing at $1500^{\circ} \mathrm{C}$ for $2 \mathrm{~h}$ in $\mathrm{Ar}$ ambient. To calculate the effects of $\mathrm{Ar}$ annealing at $1500^{\circ} \mathrm{C}$, the same parameters obtained in this study are used except that $F_{0}=0$ (no additional emission of interstitials during the Ar annealing). As shown in Fig. 13, the $\mathrm{Z}_{1 / 2}$ center is eliminated to the deeper region by the subsequent annealing. The experimental data shown as symbols (reverse triangles: after oxidation; closed circles: after oxidation followed by $\mathrm{Ar}$ annealing at $1500^{\circ} \mathrm{C}$ ) clearly agree with the predicted lines, which indicates that the present analytical model is useful for predicting trap distributions not only after oxidation but also after subsequent Ar annealing. In addition, this annealing reduces the HK0 center generated in p-type $\mathrm{SiC}$ by thermal oxidation, which also means that residual interstitials further diffuse to the deeper region and promote the $Z_{1 / 2}$ reduction by the subsequent annealing.

(iii) Higher-temperature oxidation: Because all parameters, $D, F_{0}$, and $\gamma$, should increase at higher temperature, oxidation at higher temperature must be effective in reduction of the $\mathrm{Z}_{1 / 2}$ centers. Figure 14 shows the depth profiles of $\mathrm{Z}_{1 / 2}$ center after oxidation at $1400^{\circ} \mathrm{C}$ for $5.5 \mathrm{~h}$ and $16.5 \mathrm{~h}$. Each line indicates the $n_{\mathrm{V}}$ profile calculated with the same parameter values, and each symbol indicates experimental data. The $\mathrm{Z}_{1 / 2}$ centers are eliminated to the depth of about $60 \mu \mathrm{m}$ after oxidation for $5.5 \mathrm{~h}$, which also agrees with the calculated result. The $Z_{1 / 2}$ centers could be further reduced but appear to remain at the depth of about $95 \mu \mathrm{m}$ after oxidation for $16.5 \mathrm{~h}$, while they are completely eliminated in the calculated result. (Calculated $n_{\mathrm{V}}$ distribution after 16.5-h oxidation is not shown because the $n_{\mathrm{V}}$ is lower than $1 \times 10^{10}$ $\mathrm{cm}^{-3}$ in the epilayer.) It should be mentioned that the interface between the epilayer and the substrate is located at the depth of about $96 \mu \mathrm{m}$ from the surface in this sample. Therefore, the data points near the interface might contain the 


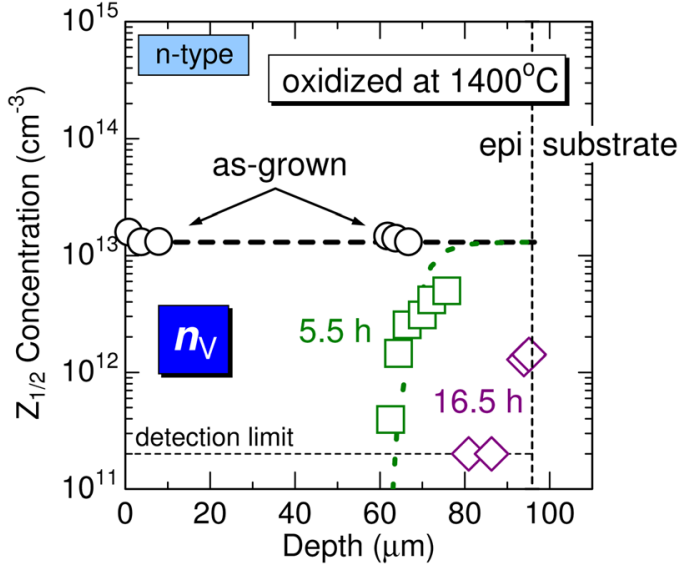

FIG. 14. (Color online) Depth profiles of $\mathrm{Z}_{1 / 2}$ center after oxidation at $1400{ }^{\circ} \mathrm{C}$ for $5.5 \mathrm{~h}$ and $16.5 \mathrm{~h}$. The dotted line indicates the $n_{\mathrm{V}}$ profile after 5.5-h oxidation calculated with the parameters in Table II and each symbol indicates experimental data. Calculated line for 16.5-h oxidation is not shown because the $n_{\mathrm{V}}$ is lower than $1 \times 10^{10} \mathrm{~cm}^{-3}$ in the $96-\mu \mathrm{m}$-thick epilayer.

substrate information (high concentration of the $\mathrm{Z}_{1 / 2}$ center must exist in the substrate). Regardless, it was clarified that thermal oxidation at $1400^{\circ} \mathrm{C}$ is a very effective way in accelerating $Z_{1 / 2}$ reduction.

In addition to the above three approaches, higher-rateoxidation processes such as wet oxidation and plasma oxidation at high temperature may be effective in reducing required oxidation time.

\section{E. Relation between carrier lifetime and $Z_{1 / 2}$ profile}

As mentioned in the introduction, the $\mathrm{Z}_{1 / 2}$ center acts as a lifetime killer in n-type $4 \mathrm{H}-\mathrm{SiC}$. Therefore, the deeper region the $\mathrm{Z}_{1 / 2}$ center is eliminated to, the longer carrier lifetime should be. Figure 15 shows $\mu$-PCD decay curves for the 96- $\mu$ m-thick n-type $\mathrm{SiC}$ epilayers $\left(N_{\mathrm{d}}: 2 \times 10^{15} \mathrm{~cm}^{-3}\right)$ on the n-type $\mathrm{SiC}$ substrates (thickness: $\sim 350 \mu \mathrm{m}$ ) after different oxidation processes. The oxidation temperature is $1300^{\circ} \mathrm{C}$ in Fig. 15 except for the signal labeled " $1400^{\circ} \mathrm{C}$." The excitation photon density is $1.1 \times 10^{14} \mathrm{~cm}^{-2}$, which leads to a high

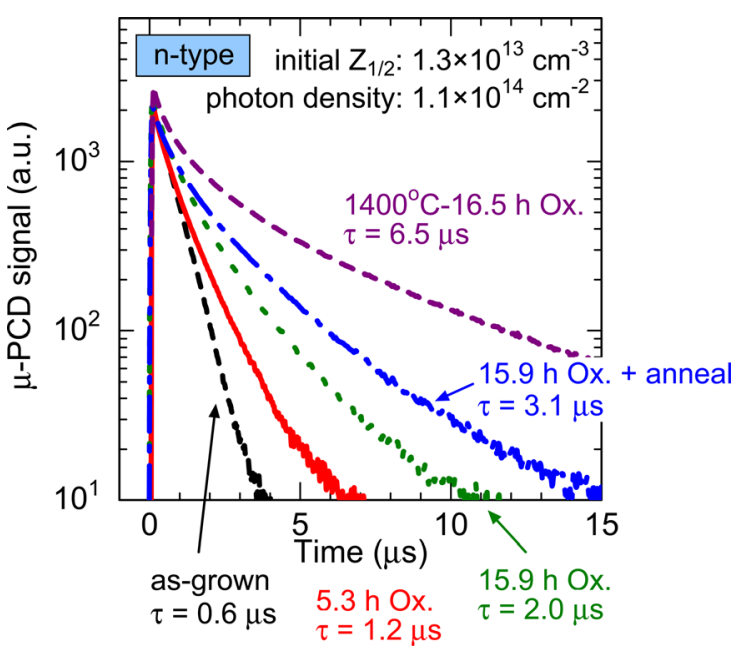

FIG. 15. (Color online) $\mu$-PCD decay curves for the 96- $\mu$ m-thick n-type $4 \mathrm{H}-\mathrm{SiC}$ epilayers after different oxidation processes. The oxidation temperature is $1300{ }^{\circ} \mathrm{C}$ except for the signal labeled " $1400^{\circ} \mathrm{C}$."

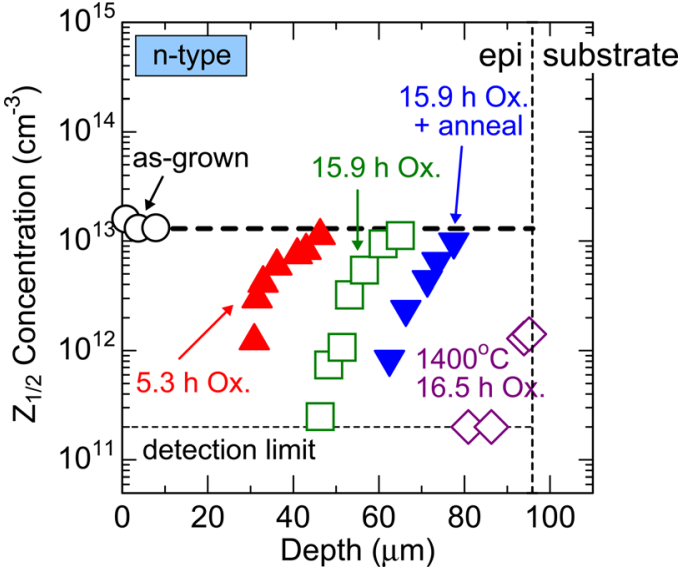

FIG. 16. (Color online) Depth profiles of $\mathrm{Z}_{1 / 2}$ concentration in the same samples as in Fig. 15.

carrier injection level of $10^{16} \mathrm{~cm}^{-3}$. The carrier lifetimes obtained from the decay curves are also described in the figure. The carrier lifetime increased from $0.6 \mu \mathrm{s}$ (as-grown) to $6.5 \mu$ s by oxidation at $1400^{\circ} \mathrm{C}$ for $16.5 \mathrm{~h}$. The carrier lifetimes are derived from the slopes of the decay curves at the points where the $\mu$-PCD signals decrease to $\mathrm{e}^{-3}$ of the initial intensity because the initial fast decay severely suffers from carrier recombination at the surface and in the substrate. ${ }^{29-31}$ Figure 16 indicates the depth profiles of $Z_{1 / 2}$ concentration in the same samples as in Fig. 15, measured by DLTS. It is obvious that a longer carrier lifetime was obtained in a sample possessing a deeper $Z_{1 / 2}$-eliminated-region.

Here, the authors tried to quantitatively estimate the relation between the carrier lifetime and the $\mathrm{Z}_{1 / 2}$ profile by a numerical simulation. It has to be noticed that the "measured" carrier lifetime does not represent the true "bulk" carrier lifetime in the epilayer itself because there are other recombination paths of excess carriers. Excess carriers generated by the excitation laser recombine at the surface as well as in the epilayer. The carriers excited in the epilayer also diffuse toward the surface and the substrate due to gradient of the carrier density, which promotes carrier recombination at the surface and in the substrate. Therefore, the measured carrier lifetime contains the effects of carrier diffusion and recombination at the surface, in the epilayer, and in the substrate. ${ }^{29-31}$

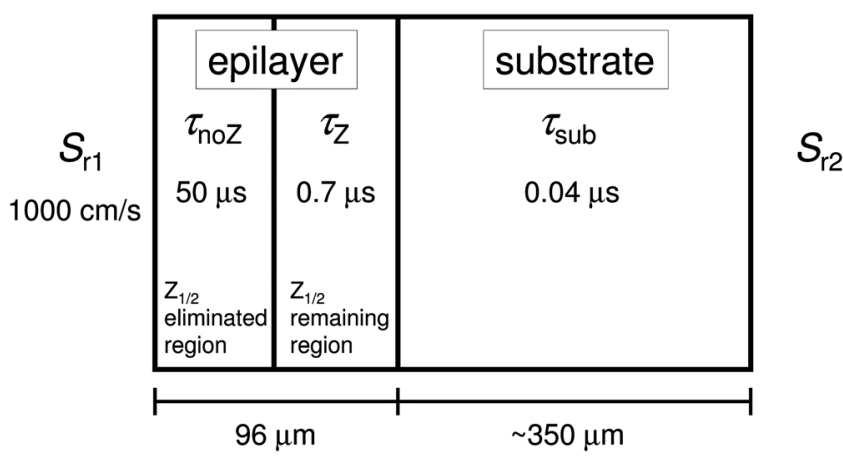

FIG. 17. Schematic illustration of an $\mathrm{SiC}$ epilayer grown on an $\mathrm{SiC}$ substrate after thermal oxidation. Carrier lifetimes in the $\mathrm{Z}_{1 / 2}$-eliminated region and the $\mathrm{Z}_{1 / 2}$-remaining region are assumed to be $50 \mu \mathrm{s}$ and $0.7 \mu \mathrm{s}$, respectively. 
TABLE III. Comparison between carrier lifetimes measured by $\mu$-PCD and effective carrier lifetimes predicted by calculation based on a diffusion equation (Ref. 31). Initial $\mathrm{Z}_{1 / 2}$ concentration is $1.3 \times 10^{13} \mathrm{~cm}^{-3}$.

\begin{tabular}{lccccc}
\hline \hline & As-grown & $1300^{\circ} \mathrm{C}-5.3$-h Ox. & $1300^{\circ} \mathrm{C}-15.9-\mathrm{h}$ Ox. & $1300^{\circ} \mathrm{C}-15.9$-h Ox. + anneal & $1400^{\circ} \mathrm{C}-16.5$-h Ox. \\
\hline Measured by $\mu$-PCD & $0.6 \mu \mathrm{s}$ & $1.2 \mu \mathrm{s}$ & $2.0 \mu \mathrm{s}$ & $3.1 \mu \mathrm{s}$ & $6.5 \mu \mathrm{s}$ \\
Predicted by calculation & $0.6 \mu \mathrm{s}$ & $1.5 \mu \mathrm{s}$ & $2.4 \mu \mathrm{s}$ & $3.2 \mu \mathrm{s}$ & $3.9 \mu \mathrm{s}$ \\
\hline \hline
\end{tabular}

In this study, a simulation model, ${ }^{31}$ which considers excited-carrier diffusion and recombination in the epilayer, substrate, and at the surface, was employed to estimate the measured carrier lifetimes. An ambipolar diffusion constant of $4.2 \mathrm{~cm}^{2} / \mathrm{s}\left(D_{\text {epi }}\right)^{32}$ was employed for the epilayer, while a standard hole diffusion constant of $0.3 \mathrm{~cm}^{2} / \mathrm{s}\left(D_{\text {sub }}\right)$ was assumed for the substrate. The optical absorption coefficient at the excitation laser wavelength $(349 \mathrm{~nm})$ was obtained as $330 \mathrm{~cm}^{-1}$ from the literature. ${ }^{33}$ Figure 17 shows a schematic illustration of an $\mathrm{SiC}$ epilayer grown on an $\mathrm{SiC}$ substrate after thermal oxidation. In this study, the epilayer was divided into two regions, the $\mathrm{Z}_{1 / 2}$-eliminated region $\left(\mathrm{Z}_{1 / 2}\right.$ concentration $<2 \times 10^{11} \mathrm{~cm}^{-3}$ ) and the $Z_{1 / 2}$-remaining region $\left(\mathrm{Z}_{1 / 2}\right.$ concentration $=1.3 \times 10^{13} \mathrm{~cm}^{-3}$ (initial value $\left.)\right)$. Taking account of results in the literature, ${ }^{31,34}$ the bulk carrier lifetime in $\mathrm{Z}_{1 / 2}$-eliminated region $\left(\tau_{\text {noZ }}\right)$ and surface recombination velocity $\left(S_{\mathrm{r} 1}\right)$ were assumed to be $50 \mu$ s (Ref. 31) and $1000 \mathrm{~cm} / \mathrm{s}$ (smooth surfaces were assumed), ${ }^{34}$ respectively. Because the backside recombination velocity $\left(S_{\mathrm{r} 2}\right)$ has very little effect on the effective lifetime due to the thick substrate (over $300 \mu \mathrm{m}$ ) and low carrier lifetime in the substrate $(0.04 \mu \mathrm{s})$, it was assumed as infinity. From the carrier lifetime measured in the as-grown sample, $0.6 \mu \mathrm{s}$, the bulk carrier lifetime in the $\mathrm{Z}_{1 / 2}$-remaining region $\left(\tau_{\mathrm{Z}}\right)$ can be estimated as $0.7 \mu \mathrm{s}$. It is mentioned again that the "measured" carrier lifetime, $0.6 \mu$ s, is shorter than the "bulk" carrier lifetime, $0.7 \mu \mathrm{s}$, due to the recombination at the surface and in the substrate. ${ }^{35}$ The boundaries between the $\mathrm{Z}_{1 / 2}$-eliminated region and the $\mathrm{Z}_{1 / 2}$-remaining region were defined to be $35 \mu \mathrm{m}$ for a sample oxidized at $1300^{\circ} \mathrm{C}$ for $5.3 \mathrm{~h}, 55 \mu \mathrm{m}$ for oxidized at $1300{ }^{\circ} \mathrm{C}$ for $15.9 \mathrm{~h}, 70 \mu \mathrm{m}$ for oxidized at $1300^{\circ} \mathrm{C}$ for $15.9 \mathrm{~h}$ followed by $\mathrm{Ar}$ annealing, and $96 \mu \mathrm{m}$ for oxidized at $1400^{\circ} \mathrm{C}$ for $16.5 \mathrm{~h}$ from the surface as shown in Fig. 16. By using the simulation model and parameters, "effective" carrier lifetimes (lifetime obtained from a decay curve) were calculated. Table III shows the comparison between the carrier lifetimes measured by $\mu$-PCD and the effective lifetime predicted by the simulation. The predicted effective lifetimes agree well with the measured carrier lifetimes. In the case of $1400{ }^{\circ} \mathrm{C}$ oxidation, however, the measured carrier lifetime $(6.5 \mu \mathrm{s})$ is longer than the predicted carrier lifetime $(3.9 \mu \mathrm{s})$. The $\mathrm{Z}_{1 / 2}$ center in the substrate near the epilayer/substrate interface might be also reduced by the intensive oxidation, which resulted in longer carrier lifetime.

\section{CONCLUSION}

To clarify the mechanism of trap reduction by thermal oxidation, the authors investigated deep levels after two trapreduction processes, thermal oxidation and $\mathrm{C}^{+}$implantation followed by Ar annealing. It was revealed that deep levels generated by thermal oxidation are the same as those generated by $\mathrm{C}^{+}$implantation and subsequent Ar-annealing. In addition, the depth profiles of generated/reduced defects represent the distribution of interstitials/vacancies after diffusion phenomena of interstitials from the surface to the $\mathrm{SiC}$ bulk region. These results indicate that the same phenomena, diffusion of interstitials, occur during these processes. Furthermore, the authors proposed an analytical model enabling prediction of $Z_{1 / 2}$ distribution after thermal oxidation using a diffusion equation. This model could reproduce the depth profiles of the $\mathrm{Z}_{1 / 2}$ center in the $\mathrm{SiC}$ with different initial$\mathrm{Z}_{1 / 2}$-concentration after oxidation at any temperature and for any oxidation time. The results suggested that long-time oxidation is required for the elimination of the $\mathrm{Z}_{1 / 2}$ center in the $\mathrm{SiC}$ when the initial $Z_{1 / 2}$-concentration is high. Thus, it is important to keep the initial $Z_{1 / 2}$-concentration, which depends on the conditions of epitaxial growth and performed device processes, low $\left(<10^{13} \mathrm{~cm}^{-3}\right)$ for achieving long carrier lifetimes. To enhance the $Z_{1 / 2}$ reduction and reduce process time, three methods, removing the oxide layer during oxidation, $1500{ }^{\circ} \mathrm{C}$ annealing after oxidation, and highertemperature oxidation, were proposed and experimentally proved to be effective. Especially, increasing oxidation temperature was the most effective for enhancement of the $\mathrm{Z}_{1 / 2}$ reduction. Post-oxidation annealing at $1500^{\circ} \mathrm{C}$ could reduce the HK0 center, which was generated in $\mathrm{SiC}$ epilayers by oxidation. Therefore, to achieve a thick $Z_{1 / 2}$-free-region for the $\mathrm{SiC}$ epilayer with high initial- $Z_{1 / 2}$-concentration $\left(>10^{13}\right.$ $\left.\mathrm{cm}^{-3}\right), 1400^{\circ} \mathrm{C}$ oxidation followed by $\mathrm{Ar}$ annealing at $1500{ }^{\circ} \mathrm{C}$ is recommended. Creating thick $Z_{1 / 2}$-free-region clearly improved the carrier lifetime, which agrees well with the values obtained by calculation based on a diffusion equation, which considers excited-carrier diffusion and recombination in the epilayer, in the substrate, and at the surface. By using the analytical models for predictions of $Z_{1 / 2}$ profile and carrier lifetime, effective carrier lifetimes can be derived from only the depth profile of initial $Z_{1 / 2}$-concentration and oxidation conditions.

\section{ACKNOWLEDGMENTS}

This work was supported by the Funding Program for World-Leading Innovative R\&D on Science and Technology (FIRST Program) and a Grant-in-Aid for Scientific Research (21226008) from the Japan Society for the Promotion of Science, and the Global COE Program (C09) from the Ministry of Education, Culture, Sports and Technology, Japan.

${ }^{1}$ T. Dalibor, G. Pensl, H. Matsunami, T. Kimoto, W. J. Choyke, A. Schöner, and N. Nordell, Physica Status Solidi (A) 162, 199 (1997). 
${ }^{2}$ C. Hemmingsson, N. T. Son, O. Kordina, J. P. Bergman, E. Janzén, J. L. Lindström, S. Savage, and N. Nordell, J. Appl. Phys. 81, 6155 (1997).

${ }^{3}$ K. Danno and T. Kimoto, J. Appl. Phys. 100, 113728 (2006).

${ }^{4}$ K. Danno and T. Kimoto, J. Appl. Phys. 101, 103704 (2007).

${ }^{5}$ T. Dalibor, H. Trageser, G. Pensl, T. Kimoto, H. Matsunami, D. Nizhner, O. Shigiltchoff, and W. J. Choyke, Mat. Sci. Eng. B 61-62, 454 (1999).

${ }^{6}$ S. Mitra, M. V. Rao, N. Papanicolaou, K. A. Jones, M. Derenge, O. W. Holland, R. D. Vispute, and S. R. Wilson, J. Appl. Phys. 95, 69 (2004).

${ }^{7}$ T. Troffer, M. Schadt, T. Frank, H. Itoh, G. Pensl, J. Heindl, H. P. Strunk, and M. Maier, Physica Status Solidi (A) 162, 277 (1997).

${ }^{8}$ D. Åberg, A. Hallén, and B. G. Svensson, Physica B: Condensed Matter 273-274, 672 (1999).

${ }^{9}$ Y. Negoro, T. Kimoto, and H. Matsunami, J. Appl. Phys. 98, 043709 (2005).

${ }^{10}$ K. Kawahara, G. Alfieri, and T. Kimoto, J. Appl. Phys. 106, 013719 (2009).

${ }^{11}$ K. Kawahara, M. Krieger, J. Suda, and T. Kimoto, J. Appl. Phys. 108, 023706 (2010).

${ }^{12}$ D. V. Lang and C. H. Henry, Phys. Rev. Lett. 35, 1525 (1975).

${ }^{13}$ P. B. Klein, B. V. Shanabrook, S. W. Huh, A. Y. Polyakov, M. Skowronski, J. J. Sumakeris, and M. J. O’Loughlin, Appl. Phys. Lett. 88, 052110 (2006).

${ }^{14}$ K. Danno, D. Nakamura, and T. Kimoto, Appl. Phys. Lett. 90, 202109 (2007).

${ }^{15}$ L. Storasta, J. P. Bergman, E. Janzén, A. Henry, and J. Lu, J. Appl. Phys. 96, 4909 (2004).

${ }^{16}$ L. Storasta, A. Henry, J. Bergman, and E. Janzén, Mater. Sci. Forum 457-460, 469 (2004).

${ }^{17}$ T. Kimoto, S. Nakazawa, K. Hashimoto, and H. Matsunami, Appl. Phys. Lett. 79, 2761 (2001).

${ }^{18}$ T. Hornos, A. Gali, and B. G. Svensson, Mater. Sci. Forum 679-680, 261 (2011).

${ }^{19}$ L. Storasta and H. Tsuchida, Appl. Phys. Lett. 90, 062116 (2007).
${ }^{20}$ L. Storasta, H. Tsuchida, T. Miyazawa, and T. Ohshima, J. Appl. Phys. 103, 013705 (2008).

${ }^{21}$ T. Hiyoshi and T. Kimoto, Appl. Phys. Expr. 2, 041101 (2009).

${ }^{22}$ Y. Hijikata, H. Yaguchi, and S. Yoshida, Appl. Phys. Expr. 2, 021203 (2009).

${ }^{23}$ K. C. Chang, N. T. Nuhfer, L. M. Porter, and Q. Wahab, Appl. Phys. Lett. 77, 2186 (2000).

${ }^{24}$ J. M. Knaup, P. Deák, T. Frauenheim, A. Gali, Z. Hajnal, and W. J. Choyke, Phys. Rev. B 71, 235321 (2005).

${ }^{25}$ S. Weiss and R. Kassing, Solid. State Electron 31, 1733 (1988).

${ }^{26}$ T. Hiyoshi and T. Kimoto, Appl. Phys. Expr. 2, 091101 (2009).

${ }^{27}$ M. Bockstedte, A. Mattausch, and O. Pankratov, Phys. Rev. B 69, 235202 (2004).

${ }^{28}$ F. Gao, W. J. Weber, M. Posselt, and V. Belko, Phys. Rev. B 69, 245205 (2004).

${ }^{29}$ P. B. Klein, R. Myers-Ward, K. Lew, B. L. VanMil, C. R. Eddy, D. K. Gaskill, A. Shrivastava, and T. S. Sudarshan, J. Appl. Phys. 108, 033713 (2010).

${ }^{30} \mathrm{P}$. Ščajev, V. Gudelis, K. Jarašiūnas, and P. B. Klein, J. Appl. Phys. 108, 023705 (2010).

${ }^{31}$ T. Kimoto, T. Hiyoshi, T. Hayashi, and J. Suda, J. Appl. Phys. 108, 083721 (2010).

${ }^{32}$ P. Grivickas, J. Linnros, and V. Grivickas, J. Mater. Res. 16, 524 (2001).

${ }^{33}$ S. G. Sridhara, R. P. Devaty, and W. J. Choyke, J. Appl. Phys. 84, 2963 (1998).

${ }^{34}$ M. Kato, A. Yoshida, and M. Ichimura, Jpn. J. Appl. Phys. 51, 02BP12 (2012).

${ }^{35}$ How to determine the $\tau_{\mathrm{Z}}$ : In the case of as-grown samples, the bulk carrier lifetime in the whole region of the epilayer is $\tau_{\mathrm{Z}}$ (there is no $\mathrm{Z}_{1 / 2}$-eliminated region). When the bulk carrier lifetime $\left(\tau_{\mathrm{Z}}\right)$ is assumed to be $0.7 \mu \mathrm{s}$, $0.6 \mu \mathrm{s}$ is obtained as calculated effective lifetime. Because this $0.6 \mu \mathrm{s}$ is equal to the measured carrier lifetime in as-grown sample, $\tau_{\mathrm{Z}}$ is determined to be $0.7 \mu \mathrm{s}$. 